\title{
Controlling the complications of diabetes: It's about the sugar
}

Previously published at www.cmaj.ca

$\mathrm{T}$ he debate over whether glucose control is a critical factor in preventing complications of type 2 diabetes mellitus is nearing its conclusion. For years, the role of so-called glucotoxicity has been challenged by theoretical arguments that the level of glycemic control might not sufficiently explain or allow prevention of complications of diabetes. Other factors, such as dyslipidemia, hypertension and cigarette smoking, are substantially responsible for these complications, and controlling these factors does reduce mortality significantly. However, mounting evidence, the most compelling of which is from a recent meta-analysis showing that intensive control of glucose prevents myocardial infarction, ${ }^{1}$ points to glucose control as the remaining culprit. When we practitioners tolerate random glucose levels above $11 \mathrm{mmol} / \mathrm{L}$ or hemoglobin $\mathrm{A}_{\mathrm{lc}}\left(\mathrm{Hb}_{\mathrm{lc}}\right)$ levels above $8 \%$ because they are "close enough," we are allowing unnecessary harm to patients.

The hypothesis of glucose toxicity states that hyperglycemia impairs both insulin secretion and sensitivity, shifting superfluous glucose from the normal glycolytic pathway to the minor sorbitol, hexosamine and glycation pathways. The accumulated end products of these pathways cause oxidative stress and inflammation in cells and blood vessel walls, resulting in pancreatic $\beta$-cell dysfunction and systemic atherosclerosis. ${ }^{2}$ Observational studies involving people with type 2 diabetes mellitus have shown a clear association between glycemic control and micro- and macro-vascular outcomes. ${ }^{3}$ However, the most pragmatic and convincing test of the glucose toxicity hypothesis comes from randomized trials of intensive glucose control.

The importance of tight control of glucose levels has been clearly established in type 1 diabetes, where there is an absolute deficiency of insulin. In the Diabetes Control and Complications Trial (DCCT) involving adults with type 1 diabetes, achieving an average $\mathrm{HbA}_{\mathrm{lc}}$ of $7 \%$ with intensive glycemic control led to a $30 \%-$ $76 \%$ reduction in the microvascular complications of retinopathy, nephropathy and neuropathy; longer follow-up showed a $57 \%$ reduction in coronary artery disease. ${ }^{4}$ In type 2 diabetes, the UK Prospective Diabetes Study (UKPDS) found significant and sustained reductions in microvascular complications in patients who were given insulin and sulfonylurea to achieve an $\mathrm{HbA}_{\mathrm{lc}}$ of $7 \% .^{5}$ Recently, longer follow-up of the same study participants found that, despite a loss of the difference in $\mathrm{HbA}_{\mathrm{lc}}$ levels after the trial, myocardial infarction was reduced by $15 \%$ among nonobese patients given sulfonylurea and insulin and by $33 \%$ among obese patients given metformin; all-cause mortality was also reduced in this group. ${ }^{6}$ Similarly, the recent Action to Control Cardiovascular Risk in Diabetes (ACCORD) trial, which achieved an average $\mathrm{HbA}_{\mathrm{lc}}$ of $6.4 \%$ in the treatment arm versus $7.5 \%$ in the control arm, found a $24 \%$ reduction in the hazard of nonfatal myocardial infarction, albeit that this trial was stopped prematurely because of increased all-cause and overall cardiovascular mortality in the intensive glycemic control group. ${ }^{7}$ These 2 trials give convincing support for the idea that hyperglycemia is at least an important cause of the excess burden of myocardial infarction in type 2 diabetes.

Residual doubt about the glucose toxicity hypothesis stems from problems with trial design, such as poor baseline risk stratification, small sample size, short treatment duration and poor delivery of the glucose control intervention. The new meta-analysis ${ }^{1}$ pooled the UKPDS and ACCORD trials with 3 other ones that addressed these prior weakness. In total, 33040 clinically stable nonhospitalized patients were enrolled and followed for about 5 years. The mean intervention $\mathrm{HbA}_{\mathrm{lc}}$ level of $6.6 \%$ was $0.9 \%$ lower among those in the intensive treatment groups. They experienced a significant $17 \%$ reduction in incidence of nonfatal myocardial infarction and a $15 \%$ reduction in coronary events overall. No effect on all-cause mortality was found, a result encumbered by heterogeneity among trials. There was, as expected, a higher incidence of hypoglycemia and severe hypoglycemia in the intensive groups, particularly in the 3 trials that reached average $\mathrm{HbA}_{\mathrm{lc}}$ levels below 7\%, a caveat that cannot be ignored.

We know enough to end the debate over whether glycemic control matters - it does. While we must continue learning how best to achieve this safely, sufficient evidence permits agreement on a provisional optimum target: an $\mathrm{HbA}_{1 \mathrm{c}}$ level of $7 \%$ for every patient with type 2 diabetes, especially for those with new-onset diabetes and for younger or healthier patients. We must redouble our efforts to hit this target by appropriately using all our weapons: weight control, exercise, oral hypoglycemic drugs and insulin therapy.

\section{Ken Flegel MDCM MSc}

Senior Associate Editor, CMAJ

With the Editorial-Writing Team (Paul C. Hébert MD MHSc, Matthew B. Stanbrook MD PhD, Noni MacDonald MD MSc, Amir Attaran LLB DPhil and Laura Eggertson BA)

This article has been peer reviewed.

Competing interests: See www.cmaj.ca/misc/edboard.shtml

Cite as CMAJ 2009. DOI:10.1503/cmaj.091354

\section{REFERENCES}

1. Ray KK, Seshasai SRK, Wijesuriya S, et al. Effect of intensive control of glucose on cardiovascular outcomes and death in patients with diabetes mellitus: a metaanalysis of randomized controlled trials. Lancet 2009;373:1765-72.

2. Giaccari A, Sorice G, Muscogiuri G. Glucose toxicity: the leading actor in the pathogenesis and clinical history of type 2 diabetes - mechanisms and potentials for treatment. Nutr Metab Cardiovasc Dis 2009;19:365-77.

3. Stratton IM, Adler AI, Neil HA, et al. Association of glycaemia with macrovascular and microvascular complications of type 2 diabetes (UKPDS 35): prospective observational study. BMJ 2000;321:405-12.

4. Nathan DM, Cleary PA, Backlund JY, et al.; Diabetes Control and Complications Trial/Epidemiology of Diabetes Interventions and Complications (DCCT/EDIC) Study Research Group. Intensive diabetes treatment and cardiovascular disease in patients with type I diabetes. N Engl J Med 2005;353:2643-53.

5. UK Prospective Diabetes Study (UKPDS) Group. Intensive blood-glucose control with sulphonylureas or insulin compared with conventional treatment and risk of complications in patients with type 2 diabetes (UKPDS 33). Lancet 1998;352:837-53.

6. Holman RR, Paul SK, Bethel MA, et al. 10-year follow-up of intensive glucose control in type 2 diabetes. N Engl J Med 2008;359:1577-89.

7. Gerstein HC, Miller ME, Byington RP, et al.; Action to Control Cardiovascular Risk in Diabetes Study Group. Effects of intensive glucose lowering in type 2 diabetes. N Engl J Med 2008;358:2545-59. 